\title{
Global Ranking, Web Visibility and Accessibility of Quranic Websites - An Evaluation Study-2015
}

\author{
Abdullah Aljumah* and Shouket Ahmad Kouchay \\ College of Computer Engineering and Sciences, Prince Sattam bin Abdul Aziz University, KSA; \\ aljumah@psau.edu.sa,sh.ahmad@psau.edu.sa
}

\begin{abstract}
The less visible contents on web are difficult to search, so web users choose other alternatives for desired information. Thus a successful website should be accessible and visible on search engines. This research aims to evaluate sample Quranic website's web accessibility level and visibility features like: traffic rank, inlinks, and Page load time, search percentage and country visitors. The websites can play an effective role in disseminating the Message of Quran. A more visible website on search engines can be accessed by big number of users and can be beneficial for the people at large scale, which helps to increase its linkage to other websites also a sample data set of 10 Quranic websites/portals were investigated for Web Visibility and Content Accessibility. It was found that the Quranexplorer.com has attained a best traffic ranking among sample dataset. Any website following the Web Content Accessibility Guidelines can disseminate its information to many users despite users having aging or any disability problem like difficulty in hearing or vision. The research revealed several accessibility issues in terms of number of problems in sample dataset and concludes with few recommendations for good quality websites/web portals.
\end{abstract}

Keywords: Accessibility, Alexa Rank, Rankings, Web Barriers, Web Visibility

\section{Introduction}

Today Internet has become essential tool for finding the information. The Internet serves hundreds of millions of users worldwide for different purposes. The visibility of a website/portal in search engines is an important metric that web site owners, competitors, scientists, and even consumers are interested in. The website/portal must compete against thousands of other Web sites with the same or similar contents or facts. If we wish to "win the battle", then we need to have an added value: we need to be found first. Researchers noted that search engine is the door to the Web today ${ }^{1}$.

Website's visibility in search engines is vital factor for high traffic rank. A well-designed site will not be successful if the potential users cannot find the site. Therefore right appearance of web contents in search engines in this competitive world has to be given a due attention. A survey by researchers ${ }^{2}$ on Korean organizations found that website metrics is a key enabler of any website's success measurement. They identify website design problems to find out whether a website meets user's needs and the website's business.

The research revealed that Web engineering topics include Web system testing and validation, quality assessment, Web metrics and Web quality attributes disciplines, performance specification and evaluation, Web usability, and user centric development etc ${ }^{3}$. The study indicates how developing websites with high visibility in search engine leads also makes their content more accessible. The research demonstrates that any search engine optimization project undertaken should include, as a prerequisite, the proper design of accessible web content, in as much as search engines will interpret the web accessibility

${ }^{*}$ Author for correspondence 
achieved as an indicator of quality and will be able to better access and index the resulting web content ${ }^{4}$. The research described arose from an investigation into the observed phenomenon that pages from accessible websites regularly appear near the top of search engine. The researcher has suggested that web visibility is important for search engine friendly website ${ }^{5}$. Another study demonstrates the visibility and accessibility of Quranic websites showing different trends and web metric features. Features like: traffic rank, inlinks, Page load time ${ }^{6}$.

The authors in study ${ }^{7}$ revealed that the web is accessible to people with same access and opportunity to all people normal or people with disabilities. "The Accessibility can be defined as the quality of a web site that makes it possible for people to use it - to find it navigable and understandable - even when they are working under limiting conditions or constraints". The Web Accessibility Initiative (WAI), in coordination with other organizations, is pursuing accessibility of the Web through five primary areas of work: technology, guidelines, tools, education and outreach, and research and development. The WAI is a primary resource for how to make your website accessible through current web standards ${ }^{8}$.

The reason for growing number of people with disabilities is as old age, sight, hearing problems or cognitive problems. Accessible web portal/sites can benefit a large number of users. This will support their website business 9 . The Quranic websites play a significant role in providing information, knowledge and facilities to people especially for Muslims.

This research aims to evaluate sample Quranic website/ portal's web accessibility level and visibility features like: traffic rank, inlinks, Page load time, search percentage, country visitors. A sample data set of 10 Quranic websites/portals was investigated for web visibility and content accessibility. So the scope of this research is limited to 10 Quranic websites/ web portals. The researchers use also Google page rank and SEMrush tool for finding the rank and backlinks in this study. The webwait.com is being used for finding the average page load time of sample data set. Software tools like SEMrush, Alexa, AChecker, Webwait, Google page rank are being used to analyze the visibility and accessibility of sample Quran Web Portals/websites.

\section{Methodology}

The Web Evaluation Methods (WEMs) study the Web as a whole by calculating statistics about the detailed use of a site and providing Web-traffic data, visibility, connectivity, ranking, and the overall impact of a site on the Web.

Alexa.com is a very powerful website for identifying the world ranking of websites. This is one of the most precise available tools to find out how well your site ranks up against millions of other websites. A website is considered a high traffic ranked and with high web visibility which has lower Alexa ranking number ${ }^{10}$.

If the goal of any evaluation method is to clarify the extent to know the ranking of a website and how much traffic it attracted, then the best way is to use Web evaluation methods like link analysis methods, thus the best way is to use a Web analytics tool such as Alexa ${ }^{11}$.

A number of researchers investigated the Web link structure to improve search results and proposed ranking metrics. When Page and Brin designed the Google search engine, they considered links as positive referrals and created a system called PageRank. Google PageRank is a link analysis algorithm that assigns a numerical weight to each hyperlink, and each page has a calculated PageRank based on the number and quality of links pointing to it ${ }^{12}$.

According to Alexa tool the web page speed is the measure of average page load time. InLinks or back links are incoming web links to any website which is very important for any website's popularity. Search percentage refers to estimated percentage of visits that came from a search engine ${ }^{10}$. The data were collected for sample 10 Quranic websites/portals for evaluation for Web Visibility and Content Accessibility.

This study investigated the 10 sampled Quranic web sites based on Alexa indexes including: traffic rank, inlinks, speed, Page load time, search percentage, country visitors. And also to examine their accessibility level by using AChecker software tool. We use other software tools also like Google page rank and SEMrush tool for finding the rank and Backlinks. We use webwait.com for finding the average page load time of sample data set.

A number of studies have investigated the accessibility of different Websites. Most studies have primarily used automated testing tools. Such as Bobby, Wave, SortSite, InFocus, APrompt, etc., which are designed to check Websites for errors that might cause accessibility problems. Although such testing software is useful in terms of identifying elements as accessible or inaccessible, they do not address the issues of functionality or usability.

There are many different online automated accessibility tools for evaluating the website's accessibility. The researchers have tested each website in the analysis and 
evaluation process with the help of renowned online accessibility software - Achecker. So Achecker tool has been selected for this study to evaluate website accessibility based on WCAG.

The data collected were analyzed and organized and also compared with the data in study ${ }^{5}$ to reveal results in accordance with the required purposes. The outcomes of this study will be beneficial for website owners and administrators in any field. The study will also help Quran website mangers and anyone interested for further research in web evaluation.

\section{Web Visibility}

A website is a window into how an organization operates. A website is a good platform to disseminate the information in any form text, audio or video. The search engines are the quick way to search any information. If website is not visible for search engines, the users can be attracted by other websites. So website should be indexed and searchable for all users ${ }^{5}$.

Research by ${ }^{13}$ says Web metrics is ranking of web, hyperlink analysis, and performance analysis. Web users choose other substitute services or contents only if the website is not visible on search engines. Any firm can lose its users if its Web site is not visible on web. Thus, it is essential to reassure that Quranic Website be given due attention for indexing and visibility in search engines.

A good quality website tends to draw more web links and more visitors. Alexa and semRush like tools are able to estimate the web metric features of any specific web portal/site 5 .

The Quran is the primary reference for any information for people in Islam. The Bing search yields 13,100,000 and Google search yields 56,800,000 results when word "Quran" was searched on 18 May 2015. Therefore there is growing need for Quranic websites to be visible and accessible on web.

There are thousands of websites for sharing and disseminating the message of Quran, if user cannot access the site, website cannot achieve its successful goal although website may have good functionality and design features ${ }^{5}$.

The researchers have decided to select ten sample Quranic web portals/sites for evaluation of web visibility features like: traffic rank, inlinks, Page load time, search percentage, country visitors within the limits of time and resources.
The first selected website among the sample dataset was Qurancomplex.org and was first registered on 27 August 2000. Using Alexa on 15 April 2015, Qurancomplex.org is ranked \#1132457 in the world. The rank has not been improved as it was in April 20145. The countries where it mostly visited are Saudi Arabia, UAE, USA. It is noted that about $22 \%$ of visits to the site came from search engines. The average page load time is 0.8 seconds which improved as it was 2.98 seconds in April 2015 . As per Alexa tool there are 954 Sites linking in to this site.

Quranflash.com is the second selected website. Its registration date is on 28 Dec 2006. Quranflash.com has an Alexa global traffic rank of 97637 which was 37,814 in April $2015^{5}$. This site has achieved a traffic rank of 1656 among users in Saudi Arabia, where about 35\% of its visitors are located. The other countries where it is mostly visited are, Ireland, Egypt, UAE, USA. There are 3,532 inbound links received by this website from other websites which decreased from previous year. The webwait speed is 0.12 seconds i.e. it takes average 0.12 seconds for this website to load. About $15 \%$ of visitors to the site are visiting through search engines which improved from previous year ${ }^{5}$.

The third selected website is understandquran.com. The website has good information especially useful for English, Urdu and Hindi speaking users. The website was first registered on September 04, 2001. Understandquran. com has an Alexa-global traffic rank of 272233 which was 198208 in April $2015^{5}$. Roughly $14 \%$ of visitors to the site are visiting through search engines. This site has achieved a traffic rank of 175931 in India, 400850 in United States and 66190 in United Kingdom. There are 308 links as per records of Alexa and 3300 backlinks according to SEMrush tool. The webwait speed is 6.64 seconds which is not considered to be good for any user-friendly website.

Qtafsir.com is the fourth analyzed website which was first registered on 28 August 2006. Qtafsir.com.s world Alexarank is 297426 which was 311,790 in April 2015 ${ }^{5}$. The site is most visited in united states and united kingdom where about $20 \%$ of its audience is located. Search engines refer about $30 \%$ of visits to the site. There are 401 Alexa links linking to this website. The webwait speed is average 2.93 seconds i.e. it takes average 2.93 seconds for this website to load.

The fifth selected website/portal Quranexplorer.com was first registered on December 12, 2005. The website has attained a top traffic rank among the sample data set using Alexa tool on 15 April 2015; Quranexplorer.com is ranked $\# 59873$ in the world. $12 \%$ of visitors are referred 
by search engines, and about of $44 \%$ of site's visitors are located in United States and Egypt both. The other countries where it is mostly visited are Malaysia, Canada, and Pakistan. There are 2,675 links linking to this website as per Alexa databank. The webwait speed is average 1.99 seconds, i.e. it takes average 1.99 seconds for this website to load the page.

The sixth selected website ATafsir.com was first registered on April 17, 2001. Altafsir.com is ranked \#152,402 in the world. Roughly $12 \%$ of visitors to the site are referred by search engines. There are 1058 links linking to this website. The webwait speed is good i.e. 0.9 seconds for opening/loading the webpage. The countries where it is mostly visited are Pakistan, Germany and United States.

The seventh selected website Kalamullah.com was first registered on October 14, 2005. Kalamullah.com's world Alexa rank is 178351 and. there are 981 inbound links linking to this website. The webwait average speed is good i.e. it takes average 0.5 seconds for this website to load the page. The countries where it mostly visited are India US, UK. About of $25 \%$ of site's visitors are located in India. About $26 \%$ of visitors to the site coming through search engines.

The eighth selected website Allahsquran.com was first registered on April 09, 2006. Allahsquran.com is ranked \#310659 in the world according to the Alexa rankings, and visitors to this site view 6 unique pages each day on average. This site has achieved a traffic rank of 587643 among users in United States where roughly $11 \%$ of its viewers are present. There are 240 inbound links as per Alexa records. The website page load time is 2.29 seconds. About $15 \%$ of visitors to the site are coming through search engines.

The ninth selected web portal Quranonline.net was first registered on Jan 31, 2005. The chosen website has drawn a 955,367 Alexa traffic ranking. Roughly 22\% it's of visitors are referred by search engines, and about of $12 \%$ of site's visitors are located in United States. There are 115 inbound links as per Alexa records. The website page load time is 0.61 seconds.

The tenth selected website/portal among dataset sample is Quranproject.org. Which was first registered on Jan 31, 2005. Quranproject.org is ranked \#1479454 in the world according to the Alexa rankings, and visitors to this site view 2.80 unique pages each day on average. This site is most visited in United States where about 57\% of its audience is located. The site has 67 inbound links according to Alexa databank. The website page load time is 1.61 seconds. About $40 \%$ of visitors to the site are coming through search engines.

The summary of various web metrics of sample dataset is shown in Table 1. The study conducted in April 2015 shows that nearly in all cases there is a slow increase in the traffic rank of the websites. The highest to lowest Alexa Global traffic ranking is shown in Figure 1. Quranexplorer.com has drawn a top traffic ranking of 59873 with 363k SEmrush back links. Understandquran.com has attained $5^{\text {th }}$ top traffic ranking of 272233 with $3.3 \mathrm{k} \mathrm{SEm}$ rush back links and Qurancomplex.org has attained $8^{\text {th }}$ top traffic ranking of 1132457 with 34247 SEmrush back links, while Quranproject.org has drawn a lowest Alexa Global traffic ranking of 4650656 among the 10 evaluated websites.

It is one of the main factors that Search engines crawl a website with priority which has more number of links. That is why Quranexplorer.com has attained Top traffic ranking of 59873 with highest 363000 back links.

Therefore website having more number of incoming links is also vital for web visibility. In this research Table 1 shows Quranonline.net and Quranproject.org have

Table 1. Summarization of significant features shown by sample data set of 10 Quranic Websites/Portals-2015

\begin{tabular}{|l|c|c|c|c|c|}
\hline \multicolumn{6}{|c|}{$\begin{array}{l}\text { Summarization of significant features shown by the sample } \\
\text { data set of 10 Quranic Websites/Portals 2015 }\end{array}$} \\
\hline Website & $\begin{array}{c}\text { Alexa } \\
\text { Rank }\end{array}$ & Speed & InLinks & $\begin{array}{c}\text { Search } \\
\%\end{array}$ & $\begin{array}{c}\text { Page } \\
\text { rank }\end{array}$ \\
\hline $\begin{array}{l}\text { Qurancom- } \\
\text { plex.org }\end{array}$ & 1132457 & 1.1 & 954 & $\mathbf{2 1 . 7}$ & 6 \\
\hline $\begin{array}{l}\text { Quranflash. } \\
\text { com }\end{array}$ & 97637 & 0.12 & 3,532 & $\mathbf{1 4 . 7}$ & 4 \\
\hline $\begin{array}{l}\text { Under- } \\
\text { standquran. } \\
\text { com }\end{array}$ & 272233 & 6.64 & 308 & $14.40 \%$ & 3 \\
\hline Qtafsir.com & 297426 & 2.93 & 401 & $30 \%$ & 5 \\
\hline $\begin{array}{l}\text { Quranex- } \\
\text { plorer.com }\end{array}$ & 59873 & 1.99 & 2,675 & $12 \%$ & 6 \\
\hline Altafsir.com & 169587 & 0.98 & 1,058 & $12 \%$ & 6 \\
\hline $\begin{array}{l}\text { Kalamullah. } \\
\text { com }\end{array}$ & 178351 & 0.5 & 981 & 26 & 4 \\
\hline $\begin{array}{l}\text { Allah- } \\
\text { squran.com }\end{array}$ & 310659 & 2.29 & 240 & $15 \%$ & 4 \\
\hline $\begin{array}{l}\text { Quranon- } \\
\text { line.net }\end{array}$ & 1467022 & 0.61 & 115 & 22 & 4 \\
\hline $\begin{array}{l}\text { Quranpro- } \\
\text { ject.org }\end{array}$ & 1479454 & 1.61 & 67 & 40 & 3 \\
\hline
\end{tabular}


attracted the less back links, 115 and 67 respectively. This could be one of reason behind their lowest rank.

Quranexplorer.com top the list where about 12\% of visits came from search engines having Google page rank 6, while Quranproject.org has lowest Google page rank 3.

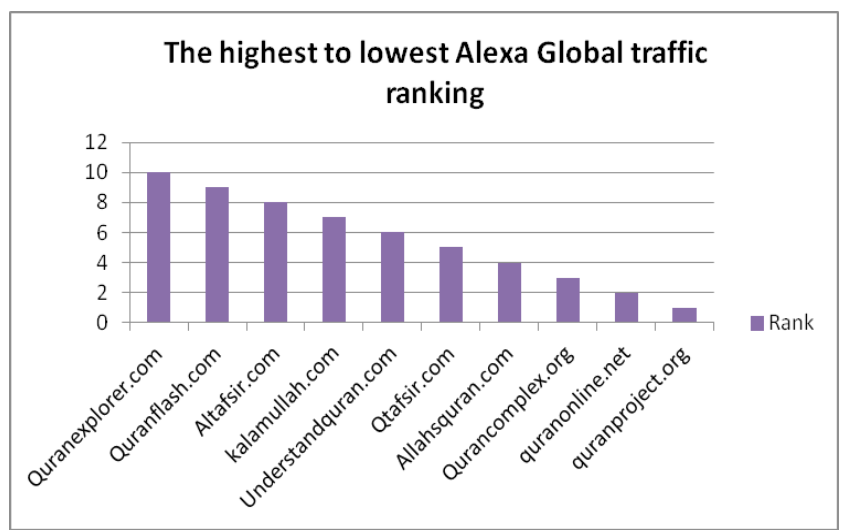

Figure 1. Sample websites with their Alexa rankings-2015.

\section{Web Accessibility}

The father of WWW T.B-Lee rightly believed "The power of the Web is in its universality. Access by everyone regardless of disability is an essential aspect ${ }^{14}$ ". It is very important that the website be accessible to all the users including the people with special needs, which can help the targeted users to avoid accessibility barriers. They also can be benefited and actively involved in web.

The study by ${ }^{15}$ concluded that there is several accessibility barriers present in some websites of small and medium enterprises in Malaysia and needs responsiveness for fixing these accessibility barriers. Some more studies on web contents accessibility are also well documented by researchers at ${ }^{5,7,15}$.

The people with special needs especially elderly or people with cognitive, hearing and vision problems can benefit and be involved actively in an accessible website/ web portal.

It is not been considered a user friendly website which has barriers for people in accessing the information due to not following the Web Content Accessibility Guidelines (WCAG).

\subsection{Web Accessibility Guidelines}

Various efforts have been made for establishing standard WCAG by many institutions with World Wide Web Consortium (WWWC) ${ }^{7}$. The WWWC established the Web
Accessibility Initiative ${ }^{16}$ in 1997 , and (WCAG) 1.0 were finalized as a recommendation in 1999. Its main objective was to support and attain Web functionality for users with special needs. However, following the accessibility standards by website developers and designers enable Web contents to be more accessible and beneficial for all users. The mission of the Web Accessibility Initiative (WAI) is to lead the Web to its full potential to be accessible, enabling people with disabilities to contribute alike on the Web. However, many websites are developed with accessibility hurdles that make it problematic or impossible for some people to use them ${ }^{14}$.

\subsection{Tools for Web Accessibility Evaluation}

There are various softwares online and offline which can be used for evaluating and detecting for Web accessibility issues. These software tools facilities to check the website's accessibility level under web accessibility guidelines. There is a vast number of accessibility tools for commercial purposes or freely available on the web such as Watch Fire Bobby, AChecker, Cynthia Says, EvalAccess etc. Some free online website/portal accessibility evaluation tools are referenced in ${ }^{17}$. These tools are very useful for developers and designers to conclude whether or not their sites follow WCAG. During the design, implementation, and maintenance phases of Web development if these tools are used sensibly, they can help the targeted users in averting accessibility barriers, fixing encountered hurdles, and improving the overall quality of Web sites ${ }^{18}$.

AChecker tool is selected for this study to evaluate website accessibility based on WCAG.

This tool is used to evaluate website's content for accessibility difficulties. It gives report about number and type of errors present in the website.

AChecker tool detects HTML webpages for conformance with accessibility rules to validate and make the contents accessed by all users. This tool helps to enhance the usability of Web portals/sites. AChecker tool recognizes three types of problems $^{19}$ :

- Known Problems: These are problems that have been identified with certainty as accessibility barriers. Web Page must be modified to remove these errors.

- Likely Problems: These are probable barriers and require changing the web page to repair these errors.

- Potential Problems: The softwares like AChecker cannot identify these problems; it needs human effort decision for identifying the errors ${ }^{19}$. 


\section{Results and Conclusion}

The study shows that nearly in all sites there is a slow increase in the traffic rank of the websites. Quranexplorer. com has drawn a Top traffic ranking of 59873 with 363k SEmrush back links. Understandquran.com has attained $5^{\text {th }}$ Top traffic ranking of 272233 with 33000 SEmrush back links and Qurancomplex.org has attained $8^{\text {th }}$ Top traffic ranking of 1132457 with 34247 SEmrush back links, While Quranproject.org has drawn a Lowest Alexa Global traffic ranking of 4650656 among the 10 evaluated websites.

Quranflash.com's Alexa global traffic rank 97637 did not improve which was 37,814 in 20145. Qurancomplex.org also did show any improvement in traffic rank since April 2014.Although its average page load time has improved since from $2014^{5}$.

Qtafsir.com's Alexa global traffic rank has shown some improvement since 2014. Quranexplorer.com's inlinks have improved as compared to 2014 in previous study ${ }^{5}$.

SEMrush rank is the rating of sites based on the number of visitors coming from the first 20 Google search results. Using SEMrush rank tool, it was found that Quranexplorer.com has good SEMrush rank of 20,327 with 363000 backlinks While Quranproject.org and Qurancomplex.org have low SEMrush rank. The sites Quranflash.com, Quranexplorer.comland Qurancomplex.org are among websites which have highest number of backlinks. The highest proportion of visits that came from search engines is for the sites Quranproject.org, Qtafsir. com and Kalamullah.com.

WebWait is a website to gauge the speed of websites. It times precisely how long the website takes to load ${ }^{20}$. The website Quranflash.com and Kalamullah.com has fastest page loading speed with good standard deviation, while Understandquran.com is slowest among the sample data set. The trend of the data can be seen clearly with median and standard deviation in Table 2.

Applying AChecker tool to the sample dataset it was found that the Quranproject.org, Altafsir.com and Kalamullah.com has highest number of Known problems in their web pages. The websites with the least number of errors are Qurancomplex.org, Quranonline.net and Quranflash.com. The Quranproject.org has 522 Known problems with 522 potential problems. The trend of the data can be seen clearly in Table 2 and Figure 2. The study reveals that Quranflash.com, Qurancomplex.org and Quranexplorer.com have less number of errors in their websites as compared to previous 2014 study $^{5}$.
Table 2. Shows the average speed of websites using WebWait tool

\begin{tabular}{|l|c|c|c|}
\hline URL & Average & Median & StdDev \\
\hline Quranflash.com & 0.12 & 0.03 & 0.14 \\
\hline kalamullah.com & 0.5 & 0.48 & 0.13 \\
\hline quranonline.net & 0.61 & 0.16 & 0.9 \\
\hline Altafsir.com & 0.98 & 0.62 & 0.7 \\
\hline Qurancomplex.org & 1.1 & 0.73 & 0.69 \\
\hline quranproject.org & 1.61 & 1.44 & 0.41 \\
\hline Quranexplorer.com & 1.99 & 1.52 & 0.9 \\
\hline Allahsquran.com & 2.29 & 2 & 0.51 \\
\hline Qtafsir.com & 2.93 & 2.66 & 0.53 \\
\hline $\begin{array}{l}\text { Understandquran. } \\
\text { com }\end{array}$ & 6.64 & 4.04 & 4.46 \\
\hline
\end{tabular}

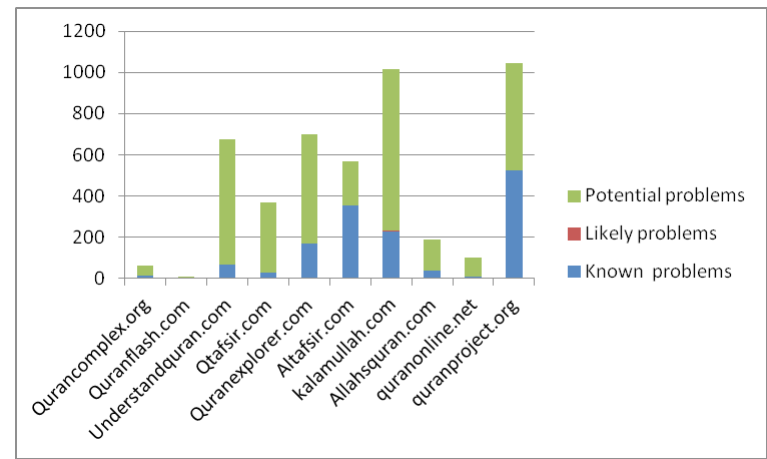

Figure 2. Number of problems shown by the sample data set of 10 Quranic Websites.

The people will face lot of usability and navigation problems on web if these problems are not fixed. The result of the study as seen in Table 3 reveals that most of the web sites for Quran are not search engine friendly and not designed consistent with the accessibility guidelines.

This study investigated the visibility and content accessibility of Quran Web sites by examining ten websites of QURAN in terms of their most web traffic volume, inbound links, country visitors, world ranking, percentage of search engines visitors and the load time for opening the websites.

According to Alexa traffic rankings Quranexplorer. com has high web visibility and ranking. Quranflash. com and Altafsir.com has attained $2^{\text {nd }}$ and $3^{\text {rd }}$ Top traffic ranking respectively, while Quranonline.net and Quranproject.org has lowest visibility and global ranking among the 10 analyzed websites. Quranexplorer.com and Quranflash.com top the list in having more back links. 
Table 3. Shows problems in Websites which are not consistent with the accessibility guidelines

\begin{tabular}{|l|c|c|c|}
\hline Website & $\begin{array}{c}\text { Known } \\
\text { problems }\end{array}$ & $\begin{array}{c}\text { Likely } \\
\text { problems }\end{array}$ & $\begin{array}{c}\text { Potential } \\
\text { problems }\end{array}$ \\
\hline quranproject.org & 522 & 0 & 522 \\
\hline Altafsir.com & 352 & 2 & 213 \\
\hline kalamullah.com & 229 & 4 & 784 \\
\hline Quranexplorer.com & 168 & 1 & 529 \\
\hline Understandquran.com & 68 & 0 & 605 \\
\hline Allahsquran.com & 39 & 1 & 147 \\
\hline Qtafsir.com & 26 & 4 & 339 \\
\hline Qurancomplex.org & 12 & 0 & 51 \\
\hline quranonline.net & 9 & 1 & 89 \\
\hline Quranflash.com & 2 & 0 & 7 \\
\hline
\end{tabular}

The study evaluated Quranproject.org most inaccessible website while Quranflash.com has less Known problems for accessibility. The findings show that without removing the accessibility barriers and improving the web visibility, usability of the websites would be badly affected. Achieving the goal of disseminating of Quranic information to all, it is recommended that the designers of Quranic websites to practice the updated WCAG guideline as point of reference. Therefore web developer's responsibility should also include constantly improving the visibility and accessibility of the Web site.

The findings of this research contribute to the present body of knowledge and for practice in developing good quality websites that take into account user interests and requirements and to use the updated web visibility and accessibility standards as point of reference in order to meet user expectations. There is a need to explore the factors which are responsible for low ranking and visibility of the Quranic websites and need necessary actions to overcome them.

\section{Acknowledgements}

This project was supported by Deanship of Scientific Research, Prince Sattam bin Abdul Aziz University under the research project No. 2014/01/2220.

\section{References}

1. Wu B, Davison BD. Undue influence: Eliminating the impact of link plagiarism on web search rankings. ACM SAC; Dijon, France. 2006.
2. Hong I. A survey of web site success metrics used by internet-dependent organizations in Korea. Internet Research, Emerald Group. 2011; 17(3):272-90.

3. Sangwan S, Kumar S. Adapting the software engineering process to web engineering process. International Journal of Computing and Business Research; 2011.

4. Moreno L, Martinez P. Overlapping factors in search engine optimization and web accessibility. Online Information Review. 2013; 37(4):564-80.

5. Kouchay SA. Evaluation of World ranking, web visibility and content accessibility of Quran Web Portals. International Journal of Quranic Research - Quranica-TechnoDaie. Science and Technology. 2014; 6.

6. Abu Bakar AB. Evaluating the accessibility and visibility of Quran Websites. Information Technology (ITSim), International Symposium; 2010.

7. Henry SL. Web accessibility: Web standards and regulatory compliance: Friends of Ed; 2006.

8. Access to disability data; 2015 May 19. Available from: http://www.infouse.com/disabilitydata/accessibility

9. Disability as a function of age; 2001 Jul. Available from: http://www.trace.wisc.edu/docs/function-aging

10. Alexa Internet; 2015 Apr 18. Available from: http://www. Alexa.com

11. Dalal Ibrahem Zahran. A comparative approach to web evaluation and website evaluation methods. International Journal of Public Information Systems; 2014.

12. Scowen G. Increased website popularity through compliance with usability guidelines [Doctoral Dissertation]. Information Science, University of Otago, New Zealand; 2007.

13. Almind TC, Ingwersen P. Informatics analysis on the WWW: Methodological. Approaches to Webometrics. J Doc. 1997; 53(4).

14. Web Accessibility; 2015 May. Available from: http://www. w3.org/standards/webdesign/accessibility

15. Wan Abdul R. Evaluating the accessibility of Small and Medium Enterprise (SME) websites in Malaysia. International Conference on user Science and Engineering; 2011.

16. Web Accessibility Initiative (WAI); 2015 May 5. Available from: http://www.w3.org/wai

17. Free Web-based website 51 accessibility evaluation tools; 2015 May. Available from: http://usabilitygeek.com/10free-web-based-web-siteaccessibility-evaluation-tools/-

18. Accessibility Evaluation Resources; 2015 May 19. Available from: http://www.w3.org/WAIIeval/Overview.html

19. Web Accessibility Checker; 2015 May 5. Available from: http://achecker.ca

20. Webwait. The FAQ; 2015 May 2. Available from: http://webwait.com/faq.html 